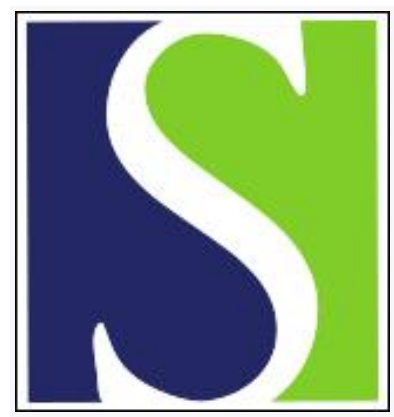

Scand J Work Environ Health 2015;41(3):280-287

https://doi.org/10.5271/sjweh.3491

Published online: 18 Mar 2015, Issue date: 01 May 2015

Psychosocial work environment and risk of ischemic stroke and coronary heart disease: a prospective longitudinal study of 75236 construction workers

by Schiöler L, Söderberg M, Rosengren A, Järvholm B, Torén K

Ischemic stroke and coronary heart disease are common and costly for society, and hence knowledge about modifiable risk factors is important. This study of a large cohort of relatively young and socially homogenous construction workers contributes to the knowledge regarding the association with the psychosocial work environment. The study found an association between stroke and active jobs and high job demands.

Affiliation: Department of Occupational and Environmental Medicine, Institution of Medicine, Sahlgrenska Academy, University of Gothenburg, Box 414, 40530 Gothenburg, Sweden. linus.schioler@amm.gu.se

Refers to the following texts of the Journal: 2004;30(2):85-128

2006;32(6):431-442 2008;34(1):40-47 1989;15(4):271-279 2013;39(3):295-301

The following article refers to this text: 2019;45(1):1-6

Key terms: coronary heart disease; ischemic stroke; job control; job demand; job strain; Karasek; longitudinal study; prospective longitudinal study; prospective study; psychosocial; psychosocial work environment

This article in PubMed: www.ncbi.nlm.nih.gov/pubmed/25785576

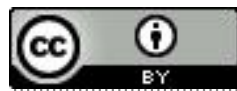




\title{
Psychosocial work environment and risk of ischemic stroke and coronary heart disease: a prospective longitudinal study of 75236 construction workers
}

\author{
by Linus Schiöler, PhD, ${ }^{1}$ Mia Söderberg, PhD, ${ }^{1}$ Annika Rosengren, MD, ${ }^{2}$ Bengt Järvholm, MD, ${ }^{3}$ Kjell
} Torén, $M D^{1,4}$

\begin{abstract}
Schiöler L, Söderberg M, Rosengren A, Järvholm B, Torén K. Psychosocial work environment and risk of ischemic stroke and coronary heart disease: a prospective longitudinal study of 75236 construction workers. Scand J Work Environ Health. 2015;41(3):280-287. doi:10.5271/sjweh.3491
\end{abstract}

\begin{abstract}
Objectives The present study aimed to investigate whether different dimensions of psychosocial stress, as measured by the job demand-control model (JDC), were associated with increased risks of ischemic stroke and coronary heart disease (CHD).

Methods A cohort of 75236 male construction workers was followed from 1989-2004. Exposure to psychosocial stress was determined by a questionnaire answered in 1989-1993. Events of ischemic stroke and CHD were found by linkage to the Swedish Causes of Death and National Patient registers. Hazard ratios (HR) were obtained from Cox regression models, adjusted for age, smoking habits, body mass index and systolic blood pressure.
\end{abstract}

Results There were 1884 cases of CHD and 739 cases of ischemic stroke. Regarding ischemic stroke, no association was found between job demands [HR 1.12, 95\% confidence interval $(95 \% \mathrm{CI}) 0.89-1.40$, highest versus lowest quintile] or job control (HR 1.04, 95\% CI 0.82-1.32, lowest versus highest quintile). Regarding CHD, job demands were associated to CHD (HR 1.18, 95\% CI 1.02-1.37, highest vs. lowest quintile), but no consistent trend was seen among quintiles. The results were inconsistent in relation to job control. The division of JDC into four categories showed no significant associations with either ischemic stroke or CHD.

Conclusions This exploratory study showed no significant associations between psychosocial work environment and ischemic stroke, and the associations between job demands and control and CHD were inconsistent and weak. The combination of job control and job demand showed no significant associations with either ischemic stroke or CHD.

Key terms Karasek; job control; job demand; job strain; prospective study.

Stroke is a major cause of death and disability in many countries (1); it is the leading cause of death in the United States (2) and, in Sweden, the third most frequent (3). Furthermore, a growing body of evidence suggests that poor psychosocial work environment is associated with impaired health, such as coronary heart disease (CHD) (4) and depression (5). CHD is another leading cause of death (6) and the literature supports an association with psychosocial factors in the work environment $(4,7-10)$. Studies investigating stroke as an outcome using psychosocial job exposure as predictors are, however, notably lacking. One reason for this is that stroke is a relatively rare condition among people still in, or only recently out of, the active workforce. Also, it is common that studies use the broader definition cerebrovascular disease, rather than stroke alone, as main outcome.

The job demand-control(-support) (JDC or JDC-S) is one of the most used and scientifically evaluated models for psychosocial exposure in the work environment $(11,12)$. When analyzing JDC-S, the single dimensions are sometimes used, but more commonly, demand and control are dichotomized into high/low and then combined into a joint model with four categories, labelled (11): high strain (high demand, low control), active

\footnotetext{
${ }^{1}$ Section of Occupational and Environmental Medicine, Institute of Medicine, Sahlgrenska Academy, University of Gothenburg, Gothenburg, Sweden.

2 Department of Molecular and Clinical Medicine, Sahlgrenska Academy, University of Gothenburg, Gothenburg, Sweden.

3 Department of Public Health and Clinical Medicine, Umeå University, Umeå, Sweden.

4 Department of Occupational and environmental medicine, Sahlgrenska University Hospital, Gothenburg, Sweden.
}

Correspondence to: Linus Schiöler, PhD, Department of Occupational and Environmental Medicine, Institution of Medicine, Sahlgrenska Academy, University of Gothenburg, Box 414, 40530 Gothenburg, Sweden. [E-mail: linus.schioler@amm.gu.se] 
(high demand, high control), passive (low demand, low control) and low-strain (low demand, high control). The combination of both high strain and low social support is commonly referred to as iso-strain.

The association between psychosocial factors in the work environment and CHD is supported in a number of systematic reviews. One, that included 31 studies, concluded that there is evidence of the association of psychosocial work characteristics (mostly measured by the JDC and effort-reward imbalance models) and CHD etiology and prognosis (9). Another review of 35 studies found consistent evidence to support the association between job strain, as defined by the JDC model, and CHD (10). In a third systematic review of 33 studies, moderate evidence was found for high psychological demands, lack of social support, and iso-strain as risk factors for CHD among men (7). A meta-analysis of 14 studies found $50 \%$ excess risk for CHD among employees with work stress (defined by either the JDC, the effort-reward imbalance, or the organizational injustice models) (4), and another one that included 13 studies found an increased risk for CHD among employees experiencing job strain (8). A Swedish study of a general population sample found an increased risk in the high strain group (13).

The current knowledge regarding the psychosocial work environment and stroke is limited. A few studies have used the single dimensions of the JDC model as predictors. One prospective cohort study displayed an almost doubled risk of cerebrovascular disease for women exposed to high demands (14). Another longitudinal study found an increased risk of cerebrovascular disease for workers in jobs with low control (15). In a longitudinal study of the entire Swedish working population aged 25-64 (16), low control increased the risk for haemorrhagic stroke and any stroke among women, but not for ischemic stroke. A study of the same population aged 30-64 with a longer follow-up (17) also showed increased stroke risk for workers in jobs with low control. One study found no association between psychosocial job exposure and increased risk of stroke (13). Studies examining the importance of social support as predictor for stroke are even sparser, with only one prospective cohort study, which found that low social support was associated with stroke for women, but not men (18).

There are only a handful studies that use the joint JDC model with four categories to examine the association between psychosocial work environment and stroke (13,14, 19-21). Only one (21) displayed significant increased risks for high strain jobs. Another study showed an increased risk for stroke among workers in an active job environment (14), but did not find any relationships between high strain and stroke.

Low socioeconomic status has consistently been identified as a predictor of stroke $(15,19,22,23)$. It has also been found that JDC strengthens the effect of socioeconomic status rather than explains it (14). One advantage with the present cohort of construction workers is that the members have similar socioeconomic status, and hence it is unlikely the results are affected by this. Considering the contradictory results, it is important to further investigate psychosocial job stress as a predictor for stroke. The present study aims to examine whether exposure to various levels of JDC-S is associated with ischemic stroke or CHD in a cohort of Swedish construction workers. It is also of interest to study an association with CHD in a relatively young and socially homogenous cohort. Although we had the a priori hypotheses that low job control and high demands is related to increased risk of ischemic stroke and CHD, the study was exploratory in nature due to the fact that we had no exact definition of these hypotheses, and also that the exposures were defined after looking at the data.

\section{Methods}

\section{Study population}

This study uses data from the Swedish Construction Industry Cohort. The Foundation for Occupational Safety and Health in the Swedish Construction Industry (Bygghälsan) was a national occupational health service established in 1968. The service invited workers for health examinations. The content of the examination and time between examinations have varied over the years. The national service ended in early 1993 . At $2-5$ years intervals, all construction workers were invited to a health examination. Over $80 \%$ of all eligible workers participated at least once. The cohort has previously been described elsewhere $(24,25)$.

During 1989-1993, a questionnaire regarding the work environment was administered in connection with the health examination. A total of 87105 persons answered the questionnaire at least once. We excluded the small group of 3405 women who answered the questionnaire, since they tended to work in administrative jobs compared to the men who predominantly worked in manual jobs. Furthermore, 2915 male office workers were excluded. After excluding 5326 subjects for missing responses for the psychological variables, 11 for missing or incorrect response date, and 212 with a history of CHD or ischemic stroke previous to baseline, a total of 75236 respondents remained.

In addition to the questionnaire, information on age, weight, height, blood pressure, smoking status and job type were available to us. Also, by linkage to the Swedish Causes of Death and National Patient registers, date and causes of deaths and diagnostic codes for inpatient visits were available until the end of 2003, providing a 
median follow-up time of 12.6 years. The baseline was defined as the date of response to the questionnaire. The Committee of Ethics at Umeå University approved the study (2010/326-32M).

\section{Psychosocial variables}

The data collection in this study was performed before the standard Job Content Questionnaire (26) was developed. There were 13 questions regarding the work situation, of which we excluded 4 (Is your work pleasant and gives you satisfaction? Are you worried about health hazards in your work? Have you had sleep disturbances during the last 12 months? Have you felt sad or depressed during the last 12 months?) since they were not directly related to job control, job demands or social support. Some of the remaining questions were also somewhat questionable in this regard. A factor analysis showed that a 3 -factor model including all the remaining questions was reasonable. The questions and the factor loadings are displayed in table 1 . The loadings that are not displayed were all $<0.2$ except for the first support question, which displayed a loading of 0.35 on factor 2. The internal consistency were good for job demands (Cronbach's $\alpha=0.70$ ) but poor for job control and social support (Cronbach's $\alpha=0.55$ and 0.57 respectively). As the variables capture dimensions similar to job demand, job control and social support, we chose to label them as such (demand, control and support for brevity). All items were scored using a scale (1-5) ranging from "seldom" to "often". Job control consisted of three items (range 3-15), job demand of four items (range 4-20), and social support of two items (range 2-10). In order to reduce the amount of missing data, control and demand were imputed using the mean of the remaining values for subjects with only one missing item.

We categorized the variables by quintiles in our main analysis. Note that the quintiles are approximate due to many observations being tied. In addition, we divided the material into Karasek's (11) four categories: high strain (high demand, low control), active (high demand, high control), passive (low demand, low control) and low-strain (low demand, high control), but due to the skewed distribution (see figure 1) we used the top quintile as a cut-off for high demands and the bottom quintile for low control, as opposed to medians as customary.

\section{Outcome variables: CHD and ischemic stroke}

CHD was defined as either hospitalization for acute myocardial infarction (AMI) using codes ICD9 410 and ICD10 I21 from the National Patient Register or death from CHD using codes ICD 9 410-414 and ICD10 I20I25 from the causes of death register. Ischemic stroke was defined as ICD9 434, 436 and ICD10 I63-I64 from either register. Only the first event of each type was used in the analysis.

\section{Statistical method}

Descriptive statistics are presented as percentages or mean values with standard deviations (SD). Cox proportional hazards regression were used for survival analysis (27). Factor analysis was used to determine which questions to include in the psychosocial scales. Factors were extracted using principle component analysis and rotated using oblique quartimax. The number of factors was chosen by inspecting the scree plot. The proportional hazards assumptions were investigated using tests and plots based on weighted residuals (28) using the R package Survival. The assumptions were found reasonable. Tests of functional form (29) indicated model misspecifications in most of the CHD models, which were handled by including the squares of the continuous covariates in the models (ie age ${ }^{2}, \mathrm{BMI}^{2}$, and systolic blood pressure $^{2}$ ). Tests for linear trend were performed by including demand, control and support as continuous covariates in Cox regression models. In the adjusted analyses, 3087 (4.1\%) subjects were excluded due to missing values on body mass index (BMI) or blood pressure. Missing values of smoking status $(\mathrm{N}=300)$ were handled by creating an additional category. Analyses were carried out using SAS 9.3 (SAS Institute Inc, Cary, NC, USA).

\section{Results}

There were 739 cases of ischemic stroke and 1884 cases of CHD and the mean age at onset was 59.3 (SD 9.4) and 58.1 (SD 8.6) respectively and were similar in all quintiles.

There was a tendency for individuals with higher demands to be older, have higher BMI, and smoke more. A similar tendency was seen for age and systolic blood pressure in relation to control, but smoking and BMI displayed no clear pattern, with the lowest and highest quintiles being the ones with the highest BMI and smoking rate. For social support there was a tendency for higher support being related to younger age, BMI, and blood pressure, but smoking rates showed no particular tendency. Descriptive statistics for the lowest, middle and highest quintiles of demands and control are displayed in tables $2 \mathrm{a}$ and $\mathrm{b}$, with middle quintiles collapsed to save space.

No significant trend was seen for demands, control, or support in relation to ischemic stroke (P-values 0.37, 0.85 and 0.25 , respectively, fully adjusted). A significant trend of higher control being protective for CHD was seen ( $\mathrm{P}=0.04$, fully adjusted), but no trend was seen for 
Table 1. The questions used to measure job demands, job control, and social support.

\begin{tabular}{llcccc}
\hline $\begin{array}{l}\text { Factor } 1 \\
\text { Loading }\end{array}$ & \multicolumn{1}{c}{ Job Demands } & $\begin{array}{l}\text { Factor 2 } \\
\text { Loading }\end{array}$ & Job Control & $\begin{array}{c}\text { Factor } 3 \\
\text { Loading }\end{array}$ & Social Support \\
\hline 0.59 & $\begin{array}{l}\text { Does your work imply taking on } \\
\text { too much responsibility? }\end{array}$ & 0.80 & $\begin{array}{l}\text { Can you decide for yourself how } \\
\text { to perform your work task? }\end{array}$ & 0.64 & $\begin{array}{l}\text { Can you talk to your management when } \\
\text { you have difficulties in your work? }\end{array}$ \\
0.78 & $\begin{array}{l}\text { Have you felt your work is } \\
\text { psychologically demanding? }\end{array}$ & 0.68 & $\begin{array}{l}\text { Do you receive timely information } \\
\text { about plans for the future, etc? }\end{array}$ & 0.91 & $\begin{array}{l}\text { Do you receive help from your work } \\
\text { colleagues when you have too much to } \\
\text { do at work? }\end{array}$ \\
$0.79 \quad \begin{array}{l}\text { Do you have trouble relaxing } \\
\text { from work during leisure time? }\end{array}$ & 0.65 & Is your work varied? & & \\
\hline $\begin{array}{l}\text { Have you ever found yourself } \\
\text { stressing out even when there's } \\
\text { plenty of time? }\end{array}$ & & & & \\
\hline
\end{tabular}
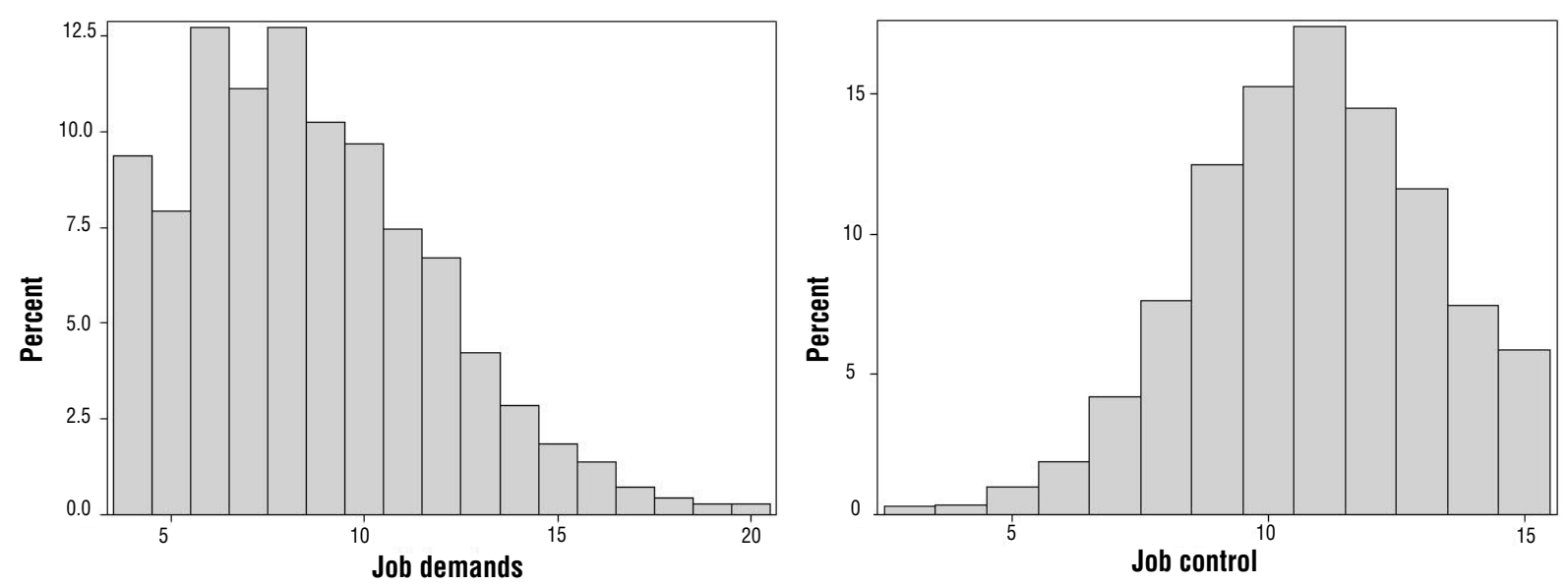

Figure 1. Distribution of job demanas ana job control.

demands or support (P-values 0.14 and 0.24 , respectively, fully adjusted).

The analysis with quintiles showed no significant association with ischemic stroke for job demands, job control, or social support and the fully adjusted model displayed similar results as the one adjusted only for age (table 3).

In the fully adjusted model, job demands showed significantly higher risk for CHD in most quintiles compared to the lowest, but there was no indication of the risk increasing on par with demands. Likewise, job control and social support did not show any clear trend among the quintiles in relation to $\mathrm{CHD}$, and the no results were significant with the exception of an increased risk seen in the middle quintile of job control (table 4).

No significant results were seen in the analysis of the four JDC categories. The low strain group consistently displayed the lowest risk with the exception of the fully adjusted analysis of ischemic stroke where the passive group were lower (table 5).

In addition, we restricted the analyses to the first five years and performed tests for trend, but no significant results were found for either ischemic stroke (P-values
$0.61,0.59$, and 0.82 for demands, control and support, respectively, fully adjusted) or CHD (P-values 0.21 , 0.06 , and 0.82 for demands, control, and support, respectively, fully adjusted).

\section{Discussion}

The most interesting results in this study were the consistent absence of associations between various dimensions of the JDC model and the risk for ischemic stroke. Regarding CHD, job demands displayed some significant association in the fully adjusted model, but the pattern was unclear and the test for trend non-significant. Further, there were inconsistent results in relation to job control. The division of JDC into four categories showed no significant associations with either ischemic stroke or CHD. In general, the results of this study were negative with estimates on the lower side compared to previous studies. Hence, it lends support to weak or non-existent associations between the psychosocial work environment and ischemic stroke or CHD. 
Table 2a. Descriptive statistics of the cohort. [BMI=body mass index; BP=blood pressure; $C H D=$ coronary heart disease; $S \mathrm{SD}=$ standard deviation.]

\begin{tabular}{|c|c|c|c|c|c|c|c|c|c|c|c|c|}
\hline & \multicolumn{12}{|c|}{ Job demands } \\
\hline & \multicolumn{4}{|c|}{ Lowest quintile } & \multicolumn{4}{|c|}{ Middle quintiles } & \multicolumn{4}{|c|}{ Highest quintile } \\
\hline & $\mathrm{N}$ & $\%$ & Mean & SD & $\mathrm{N}$ & $\%$ & Mean & SD & $\mathrm{N}$ & $\%$ & Mean & SD \\
\hline Age & & & 35.3 & 12.7 & & & 36.2 & 12.1 & & & 39.1 & 11.3 \\
\hline $\mathrm{BMI}$ & & & 24.8 & 3.2 & & & 24.8 & 3.2 & & & 25.2 & 3.2 \\
\hline Systolic BP & & & 130.5 & 13.6 & & & 130.0 & 13.7 & & & 130.1 & 13.9 \\
\hline \multicolumn{13}{|l|}{ Smoking habits } \\
\hline Non-smoker & 7629 & 58.8 & & & 23570 & 55.5 & & & 9430 & 48.4 & & \\
\hline Current smoker & 3295 & 25.4 & & & 11146 & 26.3 & & & 5908 & 30.3 & & \\
\hline $\begin{array}{l}\text { Ex-smoker } \\
\text { Ischemic stroke }\end{array}$ & 2055 & 15.8 & & & 7744 & 18.2 & & & 4159 & 21.3 & & \\
\hline Cases & 120 & & & & 383 & & & & 236 & & & \\
\hline Person years at risk & 162015 & & & & 529288 & & & & 242861 & & & \\
\hline Incidence rate a & 0.7 & & & & 0.7 & & & & 1.0 & & & \\
\hline \multicolumn{13}{|l|}{$\mathrm{CHD}$} \\
\hline Cases & 272 & & & & 1033 & & & & 579 & & & \\
\hline Person years at risk & 161497 & & & & 526787 & & & & 241422 & & & \\
\hline Incidence rate a & 1.7 & & & & 2.0 & & & & 2.4 & & & \\
\hline
\end{tabular}

a Per 1000 person years.

Table 2b. Descriptive statistics of the cohort. [BMI=body mass index; BP=blood pressure; $\mathrm{CHD}=$ coronary heart disease; $\mathrm{SD}=\mathrm{standard}$ deviation.]

\begin{tabular}{|c|c|c|c|c|c|c|c|c|c|c|c|c|c|c|c|c|}
\hline & \multicolumn{12}{|c|}{ Job control } & \multicolumn{4}{|c|}{ Overall } \\
\hline & \multicolumn{4}{|c|}{ Lowest quintile } & \multicolumn{4}{|c|}{ Middle quintiles } & \multicolumn{4}{|c|}{ Highest Quintile } & & & & \\
\hline & $\mathrm{N}$ & $\%$ & Mean & $\mathrm{SD}$ & $\mathrm{N}$ & $\%$ & Mean & SD & $\mathrm{N}$ & $\%$ & Mean & $\mathrm{SD}$ & $\mathrm{N}$ & $\%$ & Mean & SD \\
\hline Age & & & 35.8 & 12.3 & & & 36.1 & 12.0 & & & 38.9 & 11.9 & & & 36.8 & 12.1 \\
\hline $\mathrm{BMI}$ & & & 25.0 & 3.3 & & & 24.8 & 3.2 & & & 25.1 & 3.2 & & & 24.9 & 3.2 \\
\hline Systolic BP & & & 129.6 & 13.8 & & & 129.9 & 13.6 & & & 130.9 & 14.1 & & & 130.1 & 13.8 \\
\hline \multicolumn{17}{|l|}{ Smoking habits } \\
\hline Non-smoker & 6061 & 52.6 & & & 24858 & 55.6 & & & 9710 & 52.0 & & & 40629 & 54.2 & & \\
\hline $\begin{array}{l}\text { Current } \\
\text { smoker }\end{array}$ & 3282 & 28.5 & & & 11885 & 26.6 & & & 5182 & 27.7 & & & 20349 & 27.2 & & \\
\hline $\begin{array}{l}\text { Ex-smoker } \\
\text { Ischemic stroke }\end{array}$ & 2175 & 18.9 & & & 7986 & 17.9 & & & 3797 & 20.3 & & & 13958 & 18.6 & & \\
\hline Cases & 109 & & & & 425 & & & & 205 & & & & 739 & & & \\
\hline $\begin{array}{l}\text { Person years } \\
\text { at risk }\end{array}$ & 143858 & & & & 557170 & & & & 233136 & & & & 934164 & & & \\
\hline Incidence rate & 0.8 & & & & 0.8 & & & & 0.9 & & & & 0.8 & & & \\
\hline \multicolumn{17}{|l|}{$\mathrm{CHD}$} \\
\hline Cases & 293 & & & & 1058 & & & & 533 & & & & 1884 & & & \\
\hline $\begin{array}{l}\text { Person years } \\
\text { at risk }\end{array}$ & 143043 & & & & 554858 & & & & 231805 & & & & 929706 & & & \\
\hline Incidence rate & 2.0 & & & & 1.9 & & & & 2.3 & & & & 2.0 & & & \\
\hline
\end{tabular}

a Per 1000 person years.

The psychosocial factors based on the JDC model were not associated with an increased risk for ischemic stroke in this study. This is somewhat in line with previous studies. Regarding high strain, two longitudinal studies have shown non-significant results with mostly marginally increased risk estimates $(13,18)$, and in another two studies there was moderately, still non-significant, increased risk $(14,19)$. In a Japanese study there are quite high risk estimates for most dimensions of the JDC model, although only significant for high strain in all types of stroke (21). Regarding job control there are some studies showing no associations in relation to ischemic stroke $(16,19)$. However, in the extended follow-up of the Swedish study of the working population, job control was associated with ischemic stroke [hazard ratio (HR) 1.12,
95\% confidence interval (95\% CI) $1.03-1.22$, highest versus lowest quartile] (17). The present study supports previous observations of a weak or no relation between ischemic stroke and low control, high demands or their combination, ie, job strain.

The associations between job demands and job control and CHD were inconsistent. Although the test for trend were significant for job control, the analysis with quintiles showed no clear pattern and only one quintile showed a significantly higher risk than the quintile of highest job control. Job demands did not display a significant trend, but all quintiles except one showed a significantly higher risk than the reference quintile (lowest demands) in the fully adjusted model. However, no clear pattern could be seen in estimates. We would 
Table 3. Risk for ischemic stroke in relation to job demands, job control, and social support. Hazard ratio (HR) and $95 \%$ confidence interval $(95 \% \mathrm{Cl})$ from Cox proportional hazard models. [BMl=body mass index.]

\begin{tabular}{|c|c|c|c|c|c|c|c|c|c|c|c|c|}
\hline \multirow{2}{*}{$\begin{array}{l}\text { Quintile } \\
(\%)\end{array}$} & \multicolumn{2}{|c|}{ Job demands $^{a}$} & \multicolumn{2}{|c|}{ Job control a } & \multicolumn{2}{|c|}{ Social support a } & \multicolumn{2}{|c|}{ Job demands $^{b}$} & \multicolumn{2}{|c|}{ Job control b } & \multicolumn{2}{|c|}{ Social support ${ }^{b}$} \\
\hline & $\mathrm{HR}$ & $95 \% \mathrm{Cl}$ & $\mathrm{HR}$ & $95 \% \mathrm{Cl}$ & $\mathrm{HR}$ & $95 \% \mathrm{Cl}$ & $\mathrm{HR}$ & $95 \% \mathrm{Cl}$ & $\mathrm{HR}$ & $95 \% \mathrm{Cl}$ & $\mathrm{HR}$ & $95 \% \mathrm{Cl}$ \\
\hline $0-20$ & ref & & 1.09 & $0.86-1.37$ & 0.91 & $0.75-1.11$ & ref & & 1.04 & $0.82-1.32$ & 0.94 & $0.77-1.15$ \\
\hline $20-40$ & 0.95 & $0.72-1.26$ & 1.06 & $0.82-1.37$ & 0.76 & $0.59-0.98$ & 0.99 & $0.75-1.32$ & 1.05 & $0.81-1.37$ & 0.82 & $0.64-1.06$ \\
\hline $40-60$ & 1.08 & $0.86-1.36$ & 1.22 & $0.97-1.53$ & 0.88 & $0.72-1.09$ & 1.12 & $0.88-1.42$ & 1.24 & $0.98-1.57$ & 0.92 & $0.74-1.14$ \\
\hline $60-80$ & 0.83 & $0.65-1.07$ & 1.07 & $0.89-1.29$ & 1 & $0.80-1.26$ & 0.83 & $0.64-1.08$ & 1.09 & $0.90-1.32$ & 1.03 & $0.82-1.31$ \\
\hline $80-100$ & 1.08 & $0.86-1.34$ & ref & & ref & & 1.12 & $0.89-1.40$ & ref & & ref & \\
\hline
\end{tabular}

a Adjusted for age and age ${ }^{2}$.

${ }^{\mathrm{b}}$ Adjusted for age, age'2, smoking, BMI, BMI², systolic blood pressure and systolic blood pressure².

Table 4. Risk for coronary heart disease in relation to job demands, job control, and social support. Hazard ratio (HR) and $95 \%$ confidence interval $(95 \% \mathrm{Cl})$ from Cox proportional hazard models. [BMI=body mass index.]

\begin{tabular}{|c|c|c|c|c|c|c|c|c|c|c|c|c|}
\hline \multirow{2}{*}{$\begin{array}{l}\text { Quintile } \\
(\%)\end{array}$} & \multicolumn{2}{|c|}{ Job demands ${ }^{a}$} & \multicolumn{2}{|c|}{ Job control a } & \multicolumn{2}{|c|}{ Social support a } & \multicolumn{2}{|c|}{ Job demands ${ }^{b}$} & \multicolumn{2}{|c|}{ Job control b } & \multicolumn{2}{|c|}{ Social support b } \\
\hline & $\mathrm{HR}$ & $95 \% \mathrm{Cl}$ & $\mathrm{HR}$ & $95 \% \mathrm{Cl}$ & $\mathrm{HR}$ & $95 \% \mathrm{Cl}$ & $\mathrm{HR}$ & $95 \% \mathrm{Cl}$ & $\mathrm{HR}$ & $95 \% \mathrm{Cl}$ & $\mathrm{HR}$ & $95 \% \mathrm{Cl}$ \\
\hline $0-20$ & ref & & 1.12 & $0.97-1.29$ & 0.98 & $0.86-1.11$ & ref & & 1.13 & $0.98-1.31$ & 1.01 & $0.89-1.15$ \\
\hline $20-40$ & 1.2 & $1.01-1.43$ & 1.07 & $0.91-1.25$ & 1 & $0.86-1.16$ & 1.26 & $1.05-1.50$ & 1.11 & $0.95-1.31$ & 1.06 & $0.91-1.23$ \\
\hline $40-60$ & 1.16 & $0.99-1.35$ & 1.17 & $1.01-1.35$ & 0.94 & $0.83-1.08$ & 1.22 & $1.04-1.42$ & 1.18 & $1.02-1.37$ & 0.99 & $0.86-1.13$ \\
\hline $60-80$ & 1.07 & $0.92-1.26$ & 0.99 & $0.88-1.12$ & 0.98 & $0.84-1.14$ & 1.12 & $0.96-1.32$ & 1.01 & $0.89-1.14$ & 0.96 & $0.83-1.13$ \\
\hline $80-100$ & 1.15 & $0.99-1.33$ & ref & & ref & & 1.18 & $1.02-1.37$ & ref & & ref & \\
\hline
\end{tabular}

a Adjusted for age and age ${ }^{2}$.

${ }^{\mathrm{b}}$ Adjusted for age, age'2, smoking, BMI, BMI'2, systolic blood pressure and systolic blood pressure².

Table 5. Risk for ischemic stroke and coronary heart disease in relation to the job control-demands categories. Hazard ratio (HR) and 95\% confidence interval $(95 \% \mathrm{Cl})$ from Cox proportional hazard models.

\begin{tabular}{|c|c|c|c|c|c|c|c|c|}
\hline & \multicolumn{4}{|c|}{ Ischemic stroke } & \multicolumn{4}{|c|}{$\mathrm{CHD}$} \\
\hline & $\mathrm{N}$ & Events (N) & $\mathrm{HR}$ & $95 \% \mathrm{Cl}$ & $\mathrm{N}$ & Events (N) & $\mathrm{HR}$ & $95 \% \mathrm{Cl}$ \\
\hline Active a $^{\text {a }}$ & 16215 & 197 & 1.12 & $0.94-1.32$ & 16215 & 479 & 1.05 & $0.94-1.16$ \\
\hline High strain a & 3387 & 39 & 1.10 & $0.79-1.53$ & 3387 & 100 & 1.10 & $0.89-1.35$ \\
\hline Passive a & 8180 & 70 & 1.03 & $0.80-1.32$ & 8180 & 193 & 1.10 & $0.94-1.28$ \\
\hline Low strain a & 47454 & 433 & ref & ref & 47454 & 1112 & ref & ref \\
\hline Active $^{b}$ & 15539 & 189 & 1.13 & $0.95-1.34$ & 15539 & 459 & 1.04 & $0.93-1.16$ \\
\hline High strain ${ }^{b}$ & 3267 & 38 & 1.10 & $0.78-1.53$ & 3267 & 96 & 1.07 & $0.87-1.33$ \\
\hline Passive ${ }^{b}$ & 7835 & 63 & 0.95 & $0.73-1.24$ & 7835 & 187 & 1.11 & $0.95-1.29$ \\
\hline Low strain ${ }^{b}$ & 45508 & 411 & ref & ref & 45508 & 1051 & ref & ref \\
\hline
\end{tabular}

a Ajusted for age and age? 2 .

${ }^{\mathrm{b}}$ Adjusted for age, age², smoking, BMI, BMI², systolic blood pressure and systolic blood pressure².

argue that the results are somewhat in line with some of the individual studies found in Eller et al (7) and give no strong evidence for an association between psychosocial work factors and CHD.

The combined four-category model, the JDC quadrants, gave weak and non-significant signals for both ischemic stroke and CHD.

This study population is a large group of Swedish male, blue-collar, construction workers, where exposure to occupational stress is measured as job strain, defined by the JDC model. Job strain differs according to socioeconomic status (SES), which then may be regarded as a confounder (30). This has been handled by adjusting for SES in the regression models. As the job-strainexposure-effect relation may be different according to SES, it is of interest to study the effect of job strain in different SES strata. The few studies analyzing the effects of job strain among blue-collar workers indicate that passive work (31), strained work (32) and high demands and low economic reward (33) are related to increased morbidity. Hence, our results were to some extent unexpected, as previous studies have indicated blue-collar workers may experience pronounced effects of job strain exposures.

Despite that the study population had a tendency towards high control and low demands, there are still enough exposed subjects to keep up a gradient in demand and control in the material. Hence, the absence of associations between the JDC measures and ischemic stroke and CHD was unexpected. If we assume an association between work-related stress and CHD, the results indicate that we did not capture the effects of 
work-related psychosocial stress in this large group of blue-collar workers. Possible reasons for this may be the non-standard questionnaire that was used, misclassifications due to the long follow-up or that the JDC model is insufficient in this population.

The exposure information was captured during 1989-1993, and follow-up was until 2003 in the present study. The long follow-up may result in misclassification of exposure due to work changes, likely resulting in too low risk estimates, which will be particularly important if the stress factor is important late in the causative chain, ie, close to the disease-onset. However, restricting the analysis to the first five years after baseline did not produce any large changes of the results.

A substantial number of both stroke and CHD cases were found, despite the cohort being relatively young. The outcomes were taken from the Swedish causes of death and national patient registers, which have a very high coverage. Ischemic stroke were used as outcome rather than a mixture of different varieties of stroke, which may be an advantage when studying the etiology of stroke. Limitations include that results may not be generalizable to women or older cohorts in the workforce. Further limitations include the use of a nonstandard questionnaire, which has not been validated, and hence it can be questioned how well we measure job control and demand. However, some of the items are similar to the standard questionnaire and the items were shown to be related in a factor analysis. Also, the results are somewhat in line with previous studies. A further limitation is that there is only a single baseline measurement of the psychosocial variables, and hence it may not reflect the work conditions later in the follow-up, which may be especially problematic due to the long follow-up.

A limitation of the present study is that only men were included in the analysis. Previous studies have shown gender differences with respect to the effect of psychosocial stress to stroke $(15,16,18,21)$, but we were unable to investigate this since there were few women in our sample. Hence, it is also uncertain if the results apply to women. Also, the distribution of predictors was skewed, in general the subjects reported low demands and high control. Although the reported psychosocial work conditions for this cohort were quite good, it may also be partly due to gendered response patterns, ie, that men are generally taught to suppress sensations, especially if they can be associated with weaknesses and occur in male-dominated cultures and groups (34). Hence, there may be a tendency to understate the psychosocial work circumstances, which may be more pronounced in a physical and male-dominated field such as construction work.

In conclusion, this exploratory study showed no significant associations between the psychosocial work environment and ischemic stroke, and the associations between job demands and control and CHD were inconsistent and weak. The combination of job control and demand showed no significant associations with either ischemic stroke or CHD.

\section{Acknowledgment}

The Swedish Research Council (VR), the Swedish Research Council for Health, Working Life and Welfare (FORTE), and the Swedish Heart and Lung Foundation jointly funded this study.

\section{References}

1. Mukherjee D, Patil CG. Epidemiology and the Global Burden of Stroke. World Neurosurg. 2011;76(6, Supplement):S85S90. http://dx.doi.org/10.1016/j.wneu.2011.07.023.

2. Henderson KM, Clark CJ, Lewis TT, Aggarwal NT, Beck $\mathrm{T}$, Guo H, et al. Psychosocial Distress and Stroke Risk in Older Adults. Stroke. 2013;44(2):367-72. http://dx.doi. org/10.1161/STROKEAHA.112.679159.

3. Sjögren B, Lönn M, Fremling K, Feychting M, Nise G, Kauppinen $T$, et al. Occupational exposure to particles and incidence of stroke. Scand J Work Environ Health. 2013;39(3):295-301. http://dx.doi.org/10.5271/sjweh.3271.

4. Kivimäki M, Virtanen M, Elovainio M, Kouvonen A, Väänänen A, Vahtera J. Work stress in the etiology of coronary heart disease - a meta-analysis. Scand J Work Environ Health. 2006;32(6):431-42. http://dx.doi.org/10.5271/sjweh.1049.

5. Bonde JPE. Psychosocial factors at work and risk of depression: a systematic review of the epidemiological evidence. Occup Environ Med. 2008;65(7):438-45. http:// dx.doi.org/10.1136/oem.2007.038430.

6. Lozano R, Naghavi M, Foreman K, Lim S, Shibuya K, Aboyans V, et al. Global and regional mortality from 235 causes of death for 20 age groups in 1990 and 2010: a systematic analysis for the Global Burden of Disease Study 2010. Lancet. 2012;380(9859):2095-128. http://dx.doi. org/10.1016/S0140-6736(12)61728-0.

7. Eller NH, Netterstrøm B, Gyntelberg F, Kristensen TS, Nielsen F, Steptoe A, et al. Work-Related Psychosocial Factors and the Development of Ischemic Heart Disease: A Systematic Review. Cardiol Rev. 2009;17(2):83-97. http://dx.doi. org/10.1097/CRD.0b013e318198c8e9.

8. Kivimäki M, Nyberg ST, Batty GD, Fransson EI, Heikkilä $\mathrm{K}$, Alfredsson L, et al. Job strain as a risk factor for coronary heart disease: a collaborative meta-analysis of individual participant data. Lancet. 2012;380(9852):1491-7. http:// dx.doi.org/10.1016/S0140-6736(12)60994-5.

9. Kuper H, Marmot M, Hemingway H. Systematic Review of Prospective Cohort Studies of Psychosocial Factors in 
the Etiology and Prognosis of Coronary Heart Disease. Semin Vasc Med. 2002;02(03):267-314. http://dx.doi. org/10.1055/s-2002-35401.

10. Belkic K, Landsbergis P, Schnall P, Baker D. Is job strain a major source of cardiovascular disease risk? Scand $\mathrm{J}$ Work Environ Health. 2004;30(2):85-128. http://dx.doi. org/10.5271/sjweh.769.

11. Karasek RA, Jr. Job Demands, Job Decision Latitude, and Mental Strain: Implications for Job Redesign. Adm Sci Q. 1979;24(2):285-308. http://dx.doi.org/10.2307/2392498.

12. Johnson JV, Hall EM. Job strain, work place social support, and cardiovascular disease: a cross-sectional study of a random sample of the Swedish working population. Am J Public Health. 1988;78(10):1336-42. http://dx.doi.org/10.2105/ AJPH.78.10.1336.

13. Torén K, Schiöler L, Giang WK, Novak M, Söderberg M, Rosengren A. A longitudinal general population-based study of job strain and risk for coronary heart disease and stroke in Swedish men. BMJ Open. 2014;4(3):e004355. http://dx.doi. org/10.1136/bmjopen-2013-004355.

14. Kivimaki M, Gimeno D, Ferrie JE, Batty GD, Oksanen T, Jokela $\mathrm{M}$, et al. Socioeconomic position, psychosocial work environment and cerebrovascular disease among women: the Finnish public sector study. Int J Epidemiol. 2009;38(5):126571. http://dx.doi.org/10.1093/ije/dyn373.

15. Virtanen SV, Notkola V. Socioeconomic inequalities in cardiovascular mortality and the role of work: a register study of Finnish men. Int J Epidemiol. 2002;31(3):614-21. http:// dx.doi.org/10.1093/ije/31.3.614.

16. Toivanen S, Hemström Ö. Is the impact of job control on stroke independent from socioeconomic status? A large-scale study of the Swedish working population. Stroke. 2008;39(4):1321-3. http://dx.doi.org/10.1161/STROKEAHA.107.495523.

17. Toivanen S. Job control and the risk of incident stroke in the working population in Sweden. Scand J Work Environ Health. 2008;34(1):40-7. http://dx.doi.org/10.5271/sjweh.1196.

18. André-Petersson L, Engström G, Hedblad B, Janzon L, Rosvall M. Social support at work and the risk of myocardial infarction and stroke in women and men. Soc Sci Med. 2007;64(4):83041. http://dx.doi.org/10.1016/j.socscimed.2006.10.020.

19. Kuper H, Adami H-O, Theorell T, Weiderpass E. The Socioeconomic Gradient in the Incidence of Stroke: A Prospective Study in Middle-Aged Women in Sweden. Stroke. 2007;38(1):27-33. http://dx.doi.org/10.1161/01. STR.0000251805.47370.91.

20. Medin J, Ekberg K, Nordlund A, Eklund J. Organisational change, job strain and increased risk of stroke? A pilot study. Work. 2008;31(4):443-9.

21. Tsutsumi A, Kayaba K, Kario K, Ishikawa S. Prospective study on occupational stress and risk of stroke. Arch Intern Med. 2009;169(1):56-61. http://dx.doi.org/10.1001/ archinternmed.2008.503.

22. Cox AM, McKevitt C, Rudd AG, Wolfe CDA. Socioeconomic status and stroke. Lancet Neurol. 2006;5(2):181-8. http:// dx.doi.org/10.1016/S1474-4422(06)70351-9.
23. Feigin VL, Lawes CMM, Bennett DA, Anderson CS Stroke epidemiology: a review of population-based studies of incidence, prevalence, and case-fatality in the late 20th century. Lancet Neurol. 2003;2(1):43-53. http://dx.doi. org/10.1016/S1474-4422(03)00266-7.

24. Torén $\mathrm{K}$, Järvholm B. Effect of occupational exposure to vapors, gases, dusts, and fumes on COPD mortality risk among swedish construction workers: A longitudinal cohort study. Chest. 2014;145(5):99--7. http://dx.doi.org/10.1378/ chest.13-1429.

25. Torén K, Bergdahl IA, Nilsson T, Järvholm B. Occupational exposure to particulate air pollution and mortality due to ischaemic heart disease and cerebrovascular disease. Occup Environ Med. 2007;64(8):515-9. http://dx.doi.org/10.1136/ oem.2006.029488.

26. Karasek R, Brisson C, Kawakami N, Houtman I, Bongers P, Amick B. The Job Content Questionnaire (JCQ): An instrument for internationally comparative assessments of psychosocial job characteristics. J Occup Health Psychol. 1998;3(4):32255. http://dx.doi.org/10.1037/1076-8998.3.4.322.

27. Cox DR. Regression models and life-tables. J R Stat Soc Ser A. 1972:187-220.

28. Grambsch PM, Therneau TM. Proportional hazards tests and diagnostics based on weighted residuals. Biometrika. 1994;81(3):515-26. http://dx.doi.org/10.1093/ biomet/81.3.515.

29. Lin DY, Wei L-J, Ying Z. Checking the Cox model with cumulative sums of martingale-based residuals. Biometrika. 1993;80(3):557-72. http://dx.doi.org/10.1093/ biomet/80.3.557.

30. Marmot MG, Bosma H, Hemingway H, Brunner E, Stansfeld S. Contribution of job control and other risk factors to social variations in coronary heart disease incidence. Lancet. 1997;350(9073):235-9. http://dx.doi.org/10.1016/S01406736(97)04244-X.

31. von Bonsdorff MB, Seitsamo J, von Bonsdorff ME, Ilmarinen J, Nygård C-H, Rantanen T. Job strain among blue-collar and white-collar employees as a determinant of total mortality: a 28-year population-based follow-up. BMJ Open. 2012;2(2). http://dx.doi.org/10.1136/bmjopen-2012-000860

32. Johnson JV, Hall EM, Theorell T. Combined effects of job strain and social isolation on cardiovascular disease morbidity and mortality in a random sample of the Swedish male working population. Scand J Work Environ Health. 1989:271-9. http:// dx.doi.org/10.5271/sjweh.1852.

33. Lynch J, Krause N, Kaplan GA, Tuomilehto J, Salonen JT. Workplace conditions, socioeconomic status, and the risk of mortality and acute myocardial infarction: the Kuopio Ischemic Heart Disease Risk Factor Study. Am J Public Health. 1997;87(4):617-22. http://dx.doi.org/10.2105/ AJPH.87.4.617.

34. Connell R. Gender: Short introductions. Cambridge: Polity Press; 2002.

Received for publication: 11 November 2014 